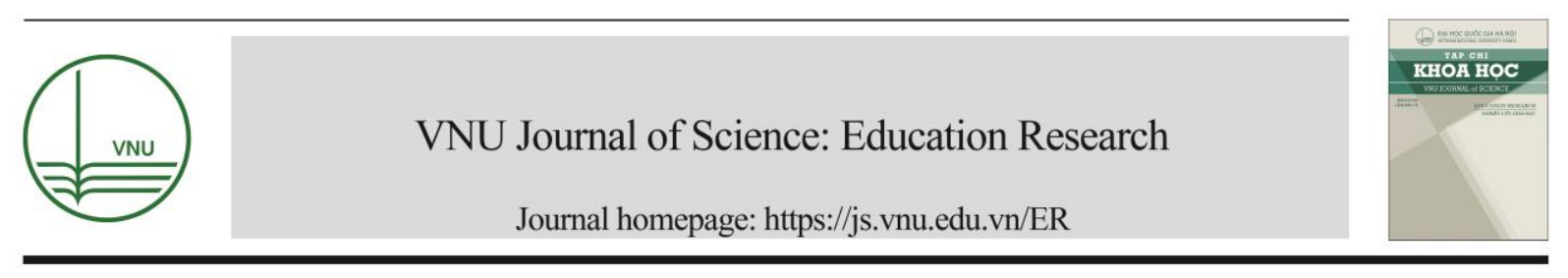

Original Article

\title{
"BRAINballs" Educational Balls - An Innovative Teaching Method in Education "Children Learn While Playing"
}

\author{
Pham Van Han ${ }^{1, *}$, Ireneusz Cichy², Sara Wawrzyniak ${ }^{2}$, Andrzej Rokita ${ }^{2}$ \\ ${ }^{1}$ An Giang University, VNU-Ho Chi Minh, 18 Ung Van Khiem, An Giang, Vietnam \\ ${ }^{2}$ University School of Physical Education in Wroctaw al. Ignacego \\ Jana Paderewskiego 35, 51-612 Wrocław, Poland
}

Received 13 July 2020

Revised 18 August 2020; Accepted 22 August 2020

\begin{abstract}
The method of teaching using "BRAINballs" educational balls in physical education classes has been researched and widely applied to children of pre-schools and primary schools in Poland, with the aim of developing motor skills, improve physical development and academic achievement of students. In this article, we present an empirical pedagogical study using BRAINballs in teaching physical education classes to second grade students at primary schools in Vietnam. The purpose of the study was to examine changes in math skills, English and physical fitness in students from the experimental class compared to the control class at two times before and after the experiment. The results of this study will be the premise for further research to prove the effectiveness and suitability of BRAINballs when applied to teaching primary school students in Vietnam.
\end{abstract}

Keywords: BRAINballs - educational balls, primary students, physical education, pedagogical experiment.

\section{Introduction}

In the current trend of integration, Vietnam is making efforts to comprehensively and fundamentally renovate education, in which the search for new and effective teaching methods to promote the teaching and learning process; help students develop comprehensively both physically and mentally become necessary. In this regard, the BRAINballs program is an

\footnotetext{
* Corresponding author.

E-mail address: pvhan@agu.edu.vn

https://doi.org/10.25073/2588-1159/vnuer.4443
}

appropriate program with many outstanding advantages to develop good qualities in the process of training people at an early stage and paving the way for development at the next stage.

BRAINballs is an educational program for preschool and elementary students that has been successfully researched and tested by researchers from the Department of Team Sports Games at the University School of Physical Education in Wroclaw, which has received acceptance and approved by the National Ministry of Education in Poland. A set of BRAINballs was entered in the official list of 
didactic aids for use in schools and designated for general and integrated education at the level of the primary school (order number: $1566 / 2003$ - on the basis of ordinance of the Ministry of National Education and Sport Diary Acts of 2002, No. 69, item 635). BRAINballs were also given a positive recommendation from the Parliament Commission for Sport [1].

Researchers found that children like moving activities and the attraction of exercises, games, especially game with balls. So they modified the traditional balls by adding letters in the alphabet, numbers and mathematical symbols on the surface of the balls [1]. In this way, educational balls were created with the first name "EDUbal", after 10 years of research being changed to "EDUball". In 2018, the English version of the educational balls named "BRAINball" was started. Despite the different names, the idea of Edubal/EDUball/BRAINball is the same; Children learn while playing! [2].

The BRAINballs set includes 100 balls used in team sports games (basketball, soccer, volleyball, handball) with five colors (yellow, green, blue, red and orange) with black letters (uppercase and lowercase letters), numbers from 0 to 9 , mathematical symbols representing addition $(+)$, subtraction $(-)$, multiplication $(*)$ and division (:), bigger symbols (>), smaller $(<)$, parentheses () and symbols (@) are drawn on their surfaces, and the balls have been resized and weighed suitable for the student's age $[2,3]$.

The main teaching method of the program is to use games and exercises that have been designed based on the natural forms of movement (running, jumping, throwing, catching,...) playing with BRAINballs in the Physical education class. Through games, students can easily grasp basic movements, motor skills and physical development. Numbers, letters and signs, as well as the color of educational balls, allow teachers to integrate instruction with a variety of content in different subjects such as: Language (Polish, English and Spanish), Mathematics, History, Geography, Biology,... [2, 4, 5].
Since the educational balls were created, there were many pedagogical studies done to determine the influence of BRANballs in physical education on motor skills and cognitive abilities of students [6-11]. The results of these studies showed that the integration of physical and intellectual activity with the educational balls has a positive effect on the psychological development of children [3]; Children participating in experiments pedagogy with EDUball has significantly improved language skills (reading and writing), math, graph tasks, motor skills, physical fitness, eye-hand coordination and time-space orientation.

BRAINballs have also been studied and applied in many countries around the world such as Germany, Czech Republic, Ukraine, Portugal, Singapore, Taiwan, United States. The results of these studies were also very proud. Currently, many countries have also taken care and pursued this educational program. In Vietnam, BRAINballs are quite new, no research has been done on this topic. In order to demonstrate that using of BRAINballs during physical education classes bring many benefits and suitable for the development of students in Vietnam. We conducted pedagogical empirical research, applying BRAINballs to teaching in physical education class for second grade students at Long Xuyen GIS International School, An Giang province. In this article, we present the steps to conduct empirical methods, assessment and testing methods and compare the initial results on the math, English and physical fitness level of students from the experimental and controll classes.

\section{Materials and Methods}

\subsection{Materials}

The sample of the study included second grade students of primary school in An Giang province, Vietnam. A total of fifty-five students (32 females and 23 males) aged 7 to 8 years in two classes participated in this study. Participants were divided into 2 classes (control and experimental). In experimental class 
consisted of twenty-eight students (16 females and 12 males); in control class consisted of twenty-seven students (16 females and 11 males). Prior to the experiment, the implementation plan and the content of instruction and evaluation received consent by the principal, teachers and parents.

\subsection{Methods}

The study was conducted during the 2019/2020 school year. The study used the method of a pedagogical experiment using parallel group technique (experimental and control classes). In the experimental class, physical education classes conducted twice a week with "BRAINballs" educational balls. Games and exercises with BRAINballs were designed according to each topic, integrated with the content in the curriculum with the consultation of the classroom teachers. In control class, physical education classes conducted twice a week using the traditional methods (without BRAINballs). In both classes (experimental and control) physical education classes were conducted by the same teacher. The teacher had a physical education degree and 10 years of teaching experience at the school. In addition, before the pedagogical experience, teacher participated in a training workshop on teaching methods with BRAINball organized by the University of Physical Education in Wrocław and An Giang University. This is an activity to help teachers better understand BRAINball, as well as how to organize and perform games and exercises with BRAINball in physical education classes.

\subsection{Measure}

To assess the difference in students' fitness level using "BRANball", the researcher used fitness tests developed by the international standard fitness testing committee [12, 13]. This is a very common fitness test, used by many researchers to assess the fitness level of students and young people in Poland and European countries [9, 14-21]. The fitness test has 8 contents: $50 \mathrm{~m}$ sprint, standing long jump, hand strength, bent arm hang, 4 x $10 \mathrm{~m}$ sprint, sit-ups, forward bend, and "600m run. However only seven out of eight content that was used for testing, content that "ran $600 \mathrm{~m} "$ was rejected because without the consent of the student's parents.

To assess students' level of math and English, the study used test questions that were designed by teachers and experts with extensive teaching experience. The test questions have been designed with diverse content suitable for the curriculum, the purpose of testing and accurately assessing the level of students at different times. It can assess students 'level at the beginning of the school year, and there are advanced sections to assess students' level at the end of the school year. The scale used to evaluate the results is a 10-point scale as prescribed by the Vietnamese Ministry of Education and Training.

To assess the reliability of the selected tests, we used the retest method. The tests were done twice by students under the same conditions, the first time 7 days away from the second. Then calculate the correlation coefficient $(r)$ of the two attempts, the results showed that all tests had correlation coefficients $\mathrm{r}>0.8$ and $\mathrm{p} \leq$ 0.05 . That meant the tests were reliable enough and allowed to use.

\subsection{Statistical Analysis}

The study used statistical software 13.0 to statistical-data processing, in which the basic calculations include: the arithmetic mean, the standard deviation. The t-student test for independent groups was conducted to determine the differences in physical fitness, math and English skills of students in the experimental and control classes. Analysis of variance for repeated measurements and the post-hoc Tukey test were conducted to determine the difference between students' English and math levels in both experimental and control classes. Statistical significance was set at $\mathrm{p}<0.05$.

\section{Results and Discussion}

The results of statistical analysis showed that the students from the experimental group 
achieved better results than the students from the control group in the variables: stading long jump (cm), flexed arm hang (s), sit- ups from a lying position (number). However, these differences were not statistically significant with $p>0.05$. Students from the control group achieved better results than students from the experimental group in the variables: running a distance of $50 \mathrm{~m}(\mathrm{~s})$, palm dynamometry $(\mathrm{kg})$, $4 \times 10 \mathrm{~m}$ shuttle run with wooden blocks (s), forward bend from a stading position on a bench $(\mathrm{cm})$. However, there was only difference in the "forward bend from a stading position on a bench $(\mathrm{cm})$ " variable between the two classes with statistical significance $\mathrm{p}=0.043$ (Table 1, Figure 1).

Table 1. Comparison of average physical fitness values obtained in experimental and control classes

\begin{tabular}{|l|l|l|l|l|l|l|l|l|}
\hline \multirow{2}{*}{ Variable } & \multicolumn{3}{|c|}{ Control } & \multicolumn{3}{|c|}{ Experimental } & \multirow{2}{*}{ p } & \multirow{2}{*}{ Difference } \\
\cline { 2 - 8 } & $\mathrm{N}$ & $\mathrm{M}$ & $\mathrm{SD}$ & $\mathrm{N}$ & $\mathrm{M}$ & $\mathrm{SD}$ & & \\
\hline 50 Run (s) & 27 & 13.32 & 1.73 & 28 & 13.48 & 1.53 & 0.706 & 0.17 \\
\hline Toe touch (cm) & 27 & 5.56 & 3.47 & 28 & 3.68 & 3.26 & 0.043 & 1.88 \\
\hline Jump (cm) & 27 & 98.96 & 12.88 & 28 & 100.64 & 13.09 & 0.633 & 1.68 \\
\hline 4 x 10 run (s) & 27 & 16.35 & 2.02 & 28 & 16.45 & 1.33 & 0.831 & 0.10 \\
\hline Dynam (kg) & 27 & 10.22 & 3.00 & 28 & 9.29 & 2.60 & 0.224 & 0.93 \\
\hline Hang (s) & 27 & 2.17 & 0.72 & 28 & 2.38 & 0.98 & 0.377 & 0.21 \\
\hline Sit-ups (num.) & 27 & 8.33 & 3.52 & 28 & 9.14 & 3.47 & 0.394 & 0.81 \\
\hline
\end{tabular}

Legend for tables 1

50 run - running a distance of $50 \mathrm{~m}$

Jump - standing long jump

Dynam - palm dynamometry

Hang - flexed arm hang
$4 \times 10$ run -4 x 10 m shuttle run with wooden blocks

Sit-ups - sit-ups from a lying position

Toe touch - forward bend from a stading position on a bench

$\mathrm{N}$ - number of participants, - arithmetic mean, SD - standard deviation
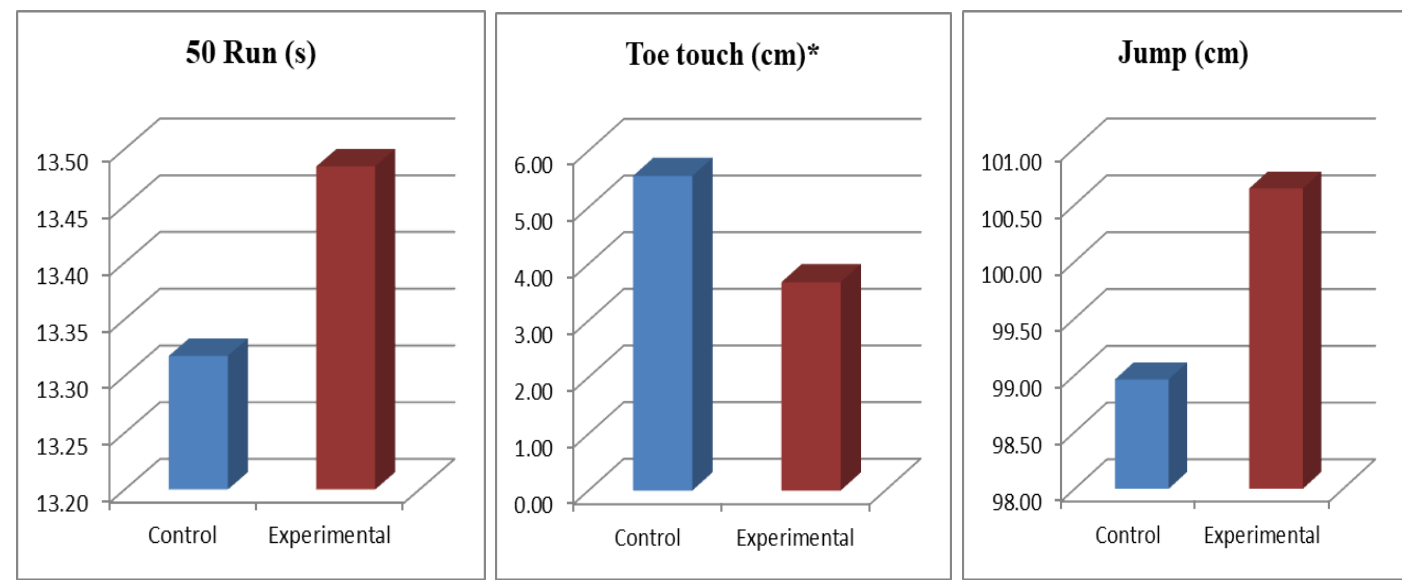

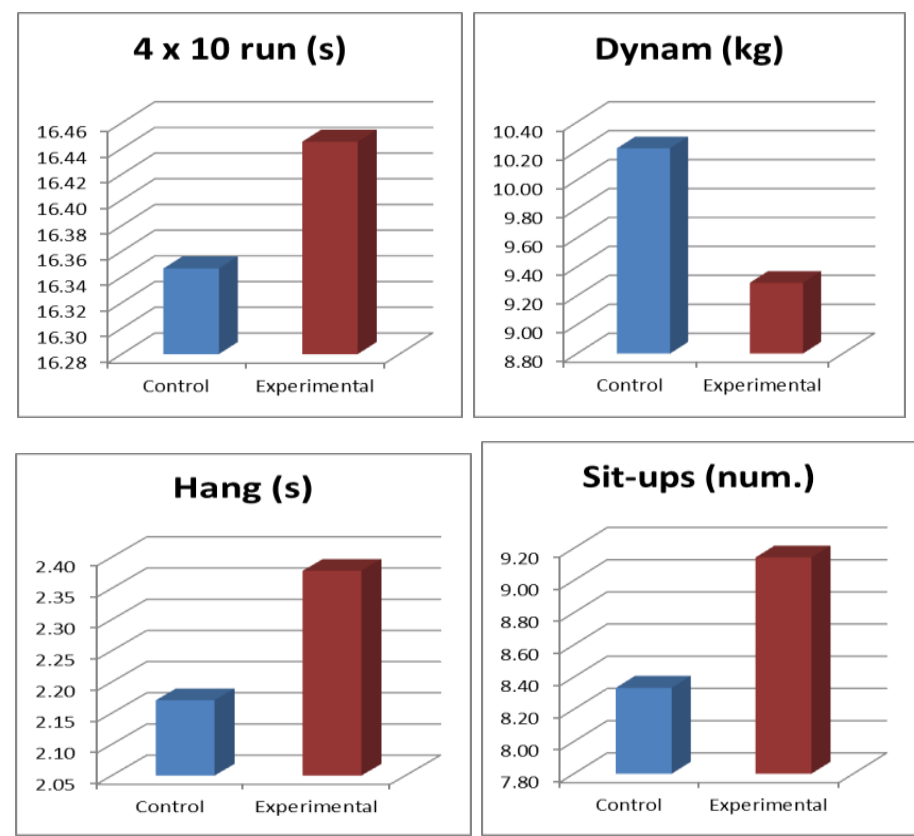

Figure 1. Results of physical fitness averages obtained in experimental and control classes.

The results of statistical analysis showed that the students from the control class achieved better results than the students from the experimental class in the math and English skills. However, these differences were not statistically significant with $p>0.05$ (Table 2, Figure 2).

Table 2. Comparison of average math and English values obtained in experimental and control classes

\begin{tabular}{|c|c|c|c|c|c|c|c|c|}
\hline \multirow{2}{*}{ Skills } & \multicolumn{3}{|c|}{ Control } & \multicolumn{3}{|c|}{ Experimental } & \multirow[b]{2}{*}{$\mathrm{p}$} & \multirow{2}{*}{ Difference } \\
\hline & $\mathrm{N}$ & $\mathrm{M}$ & SD & $\mathrm{N}$ & $\mathrm{M}$ & SD & & \\
\hline Math & 27 & 5.20 & 1.62 & 28 & 4.75 & 1.04 & 0.220 & 0.45 \\
\hline English & 27 & 5.41 & 1.28 & 28 & 4.86 & 1.35 & 0.126 & 0.55 \\
\hline
\end{tabular}

$\mathrm{N}$ - number of participants, - arithmetic mean, $\mathrm{SD}$ - standard deviation

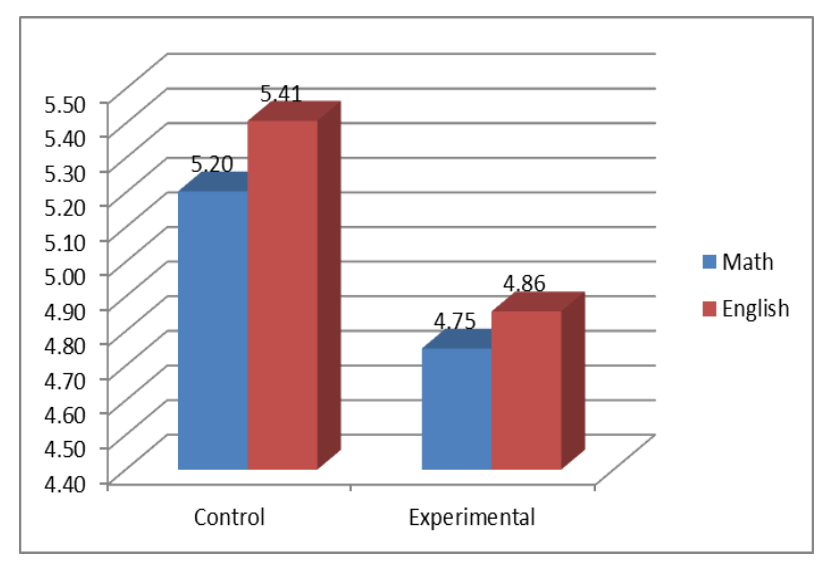

Figure 2. Results of math and English averages obtained in experimental and control classes. 
The main purpose of the study is to understand the relationship of the development of math skills, English skills and physical fitness of elementary school students in Vietnam when participating in physical education classes with BRAINballs. The method of a pedagogical experiment using parallel group technique (experimental and control classes) has been conducted to examine the effect of using BRAINballs to integrate math and English teaching in physical education classes compared to traditional teaching methods. The results obtained at the first examination (before the experiment) showed that there were no significant differences in the level of students between the experimental and control classes. That was meant to compare changes in students' levels from experimental and control classes after the experiment, we need to conduct a similar measurement at the end of the school year.

After many years of research, the BRAINballs program has proved its benefits when it is applied to students in Poland and some countries around the world. Researchers have agreed that under the concept of "Children learn while playing", the BRAINballs program not only helps students significantly improve academic achievement but also develop motor and physical skills [9, 11]. Classes integrated with physical education help students increase learning time. The content that was taught in the classroom has been consolidated in the physical education class, which means that students have learned the content twice in different classes, thereby helping to master the knowledge of the lesson. In addition, the method of using games and exercises with educational balls helps the classroom become lively and interesting, students actively participate in motor activities, from which motor skills are formed and developed easily.

In this study, we have found that there were a number of limitations that need to be noted during implementation. First, teachers and students will be confused when they first encounter the teaching and learning method with BRAINballs. This has been overcome by organizing training for teachers and students on teaching and learning methods with BRAINballs. Second, the sample size of the study is relatively small, so it can affect the research results. However, with a suitable and well-designed research method, along with a consistent coordination between classroom teachers and physical education teachers, we are confident that research results will be achieved with high accuracy and reliability.

\section{Conclusion}

BRAINballs is an innovative teaching method that can integrate content from different subjects into the same lesson to stimulate students' cognitive, emotional and physical areas. The content and method of teaching with BRAINballs is simple, flexible, many ways to play and very suitable for elementary school students. Students while taking physical education classes along with educational balls, learn more about colors, alphabet letters, numbers, math symbols, punctuation and many other principles related to language education and math. At the same time, students also shape their ability to coordinate movement, physical development, and other skills necessary to apply it in everyday life.

BRAINballs is an effective teaching solution for elementary students in Vietnam in the current period. However, in order to be able to apply teaching in Vietnam, BRAINballs need to be studied with a variety of subjects and variety of forms in order to prove the effectiveness and suitability for the development of students in Vietnam.

\section{Reference}

[1] A. Rokita, I. Cichy, "Edubal" educational balls: I learn While Playing! The Global Journal of Health and Physical Education Pedagogy 2(4) (2013) 289-297.

[2] A. Rokita, S. Wawrzyniak, I. Cichy, Learning by playing! 100 games and exercises of BRAINballs, University School of Physical Education in Wrocław, Poland, 2018. 
[3] A. Rokita, I. Cichy, S. Wawrzyniak, M. Korbecki, Eduball Games and Sports! A Guide for Primary School Teachers and Cooperating Physical education Teachers Carrying out the "Little Champion" Program, Ministry of Sport and Tourism, Marshal Office of the Lower Silesia Region, School Sports Association "Dolny Śląsk", Wrocław, Poland, 2017.

[4] A. Rokita, T. Rzepa, Playing - I'm learning. Educational balls in integrated education, University School of Physical Education in Wrocław, Poland, 2002 (in Polish).

[5] A. Rokita, T. Rzepa, Educational balls in early school education, University School of Physical Education in Wrocław, Poland, 2005 (in Polish).

[6] I. Cichy, Physical fitness, general body coordination and educational competences of first grade students of primary school taught by traditional and non-traditional programs (in Polish), Doctoral dissertation, University School of Physical Education in Wrocław, Poland, 2010.

[7] M. Kaczmarczyk, Movement classes with educational balls "Edubal" and the knowledge and mathematical skills of first grade students of primary school (in Polish), Doctoral dissertation, University School of Physical Education in Wrocław, Poland, 2013.

[8] A. Krysmann, The use of "edubal" educational balls in integrated education and reading and writing skills of dyslexic students (in Polish), Doctoral dissertation, University School of Physical Education in Wrocław, Poland, 2012.

[9] A. Rokita, Physical education with the educational ball "edubal" in the integrated education and physical fitness and the students' ability to read and write (in Polish), Studia I Monografie, University School of Physical Education in Wrocław, Poland, 2008.

[10] S. Wawrzyniak, Graphomotor skills, eye-hand coor-dination and time-space orientation of first grade elementary school children participating in physical education classes with the educational balls Edubal (in Polish), Doctoral dissertation, University School of Physical Education in Wrocław, Poland, 2016.

[11] S. Wawrzyniak, A. Rokita, D. Pawlik, Temporalspatial orientation in first-grade pupils from elementary school participating in physical education classes using Edubal educational balls, Baltic Journal of Health and Physical Activity 7(2) (2015) 33-43.
[12] J. Drabik, Testing physical fitness with school student, University School of Physical Education in Wrocław in Gdansk, Poland, 1992.

[13] L.A. Larson, An international research program for the standardization of physical fitness tests, Journal of Sports Science and Medicine 4 (1966) 259-261.

[14] I. Cichy, A. Rokita, The use of the "EDUBALL" Educational Ball in rural and urban primary school and the physical fitness levels of children, Human Movement 13(3) (2012) 247-257. https://doi.org/10.2478/v10038-012-0029-y.

[15] K. Tomasz, W. Filip, C. Mirosława, Z. Walery, Somatic and physical fitness evaluation of primary school no 2 students in Szubin, Journal of Health Sciences 4(7) (2014) 47-70.

[16] M. Szark-Eckardt, M. Kuska, H. Żukowska, M. Pezala, M. Napierała, Dimorphism of motor skills of 17-19-year-old students from Bydgoszcz, Journal of Education, Health and Sport 8(12) (2018) 59-68. https://doi.org/10.5281/zenodo.1873967.

[17] J. Wojciech, N. Marek, C. Mirosława, M. Radosław, Z. Walery, Impact of summer break on the efficiency of students under the age of 18 years in the agricultural school of lifelong learning centre in przemystka, Journal of health sciences 3 (12) (2013) 55-66.

[18] M. Klimczyk, W. Kędzierski, Morphological characteristics and physical fitness 7-years old children attending School No. 1 in Sepólno Krajeńskie, Journal of Education, Health and Sport 6(7) (2016) 277-291. https://doi.org/10.5281/zenodo.57673.

[19] K. Byzdra, A. Skrzypczyńska, M. Piątek, R. Stępniak, Physical activity and development of physical fitness at boys at age between 13 and 15 years old, Journal of Health Sciences 3 (10) (2013) 261-274.

[20] J. Dobosz, D. Mayorga-Vega, J. Viciana, Percentile values of physical fitness levels among Polish children aged 7 to 19 years - A populationbased study, Central European Journal Public Health 23(4) (2015) 340-351.

[21] M. Popowczak, A. Rokita, I. Cichy, P. Chmura, Physical fitness of children aged 10 years participating in physical education classes enriched with coordination exercises, Antromotoryka 62 (2013) 55-65. https://doi.org/ $10.5604 / 17310652.1091385$. 